\title{
ALGUNOS DESTELLOS DE LA LUZ DE SPINOZA: DE UNA METÁFORA DE DILTHEY AL RELÁMPAGO EN ROMAIN ROLLAND
}

\section{SOME GLIMMERS OF THE LIGHT OF SPINOZA: FROM A METAPHOR OF DILTHEY TO LIGHTNING IN ROMAIN ROLLAND}

\author{
PiLAR BENITO OLALLA \\ UNED
}

\begin{abstract}
RESUMEN: La figura y la obra de Spinoza han despertado curiosidad, admiración y hasta veneración en numerosos intelectuales, no sólo filósofos, sino también literatos. La descripción de la experiencia de algunos de ellos acerca del encuentro con el filósofo holandés suele abundar en metáforas lumínicas, cristalinas, e incluso ígneas. En este artículo, parto de una metáfora de Dilthey que asemeja la filosofía de Spinoza con un cristal brillante y transparente. A continuación, planteo la doble dimensión interpretativa que pueden albergar esos dos adjetivos en relación con la comprensión de las ideas de Spinoza: respectivamente, la afectividad (brillante) y la racionalidad (transparente). Y, finalmente, analizo en detalle uno de los escritos que considero más significativos sobre el carácter casi sagrado de iluminación fulgurante que provoca la lectura de las obras de Spinoza: L'éclair de Spinoza, de Romain Rolland.
\end{abstract}

PALABRAS CLAVE: Cristal, brillante, transparente, relámpago, eternidad, sustancia, sentimiento oceánico.

ABSTRACT: Spinoza's character and work have aroused the curiosity, approval and even worship of countless academics, philosophers, and men of letters. Their descriptions of their encounters with the Dutch philosopher are usually loaded with luminous as well as crystalline and even igneous metaphors. In this article, I will start out from one of Dilthey's metaphors that compares Spinoza's philosophy to a sparkling, transparent crystal. I will then consider the double interpretational dimension that these two adjectives might have in relation to understanding Spinoza's views: respectively, emotion (sparkling), and reasoning (transparent). Finally, I will discuss in detail a writing that 
I believe to be one of the most relevant ones about the almost sacred nature of the gleaming illumination that stems from reading Spinoza's works: L'éclair de Spinoza, by Romain Rolland. feeling.

KEYWORDS: Crystal, sparkling, transparent, lightning, eternity, substance, oceanic

\section{Introducción}

Baruch Spinoza es un filósofo críptico, enigmático y poco conocido para el gran público. Autor de una obra de tan difícil lectura e interpretación como la Ética, ha despertado, sin embargo, notable curiosidad en muchos intelectuales y algo más en algunos de ellos: una profunda y misteriosa admiración. El estudio de las razones de esa especial querencia se suele centrar en algún literato en concreto, y un ejemplo reiterado lo constituye Jorge Luis Borges, cuyos dos sonetos dedicados a Spinoza son de sobra conocidos y objeto de numerosos análisis, además de su constante interés por el filósofo judío, pulidor de lentes, manifestado en algunas alusiones presentes en sus escritos, en entrevistas y hasta en una conferencia pronunciada en la sede de la comunidad judía de Buenos Aires.

Un reputado spinozista, Pierre-François Moreau, aglutina los motivos del afecto hacia Spinoza por parte de artistas no-filósofos y, en general, de la «consciencia filosófica común», en seis escenarios, que implican, a su vez, seis retratos del filósofo, donde se mezclan leyenda y realidad tejiendo una hagiografía en torno a ese modelo: el virtuoso, el panteísta, el judío laico, el disidente radical, el crítico de los prejuicios y de la conciencia, el personaje bifronte cuyas ideas se pueden interpretar desde extremos opuestos ${ }^{1}$. Al final de su agudo análisis de estos retratos, los cuales poseen al mismo tiempo dosis de verdad y ficción, Moreau se pregunta el porqué de este anclaje racional y afectivo con Spinoza y no respecto a cualquier otro filósofo, y nos propone su propia hipótesis: el elemento común que unifica todos esos escenarios en torno al filósofo holandés es la atracción por «el brillo de la escritura spinoziana» ${ }^{2}$; una escritura seca desde un punto de vista literario, pero acerada, intensa, «contundente», e instrumento de «una

\footnotetext{
${ }^{1}$ Cf. Pierre-François Moreau, « ¿Por qué fascina Spinoza a los escritores?», Cuadernos del Seminario Spinoza, n 18, 2004.

${ }^{2}$ Ibidem, p. 14.
} 
estilística de la negación» ${ }^{3}$. Según Moreau, esa negación de lo habitual que rompe expectativas y lugares comunes, se halla presente tanto en sus escritos, como en la vida del propio Spinoza, de marcada originalidad e insólita perseverancia frente a lo establecido por la sociedad:

«Sólo conocemos algunos hechos de la vida de Spinoza, pero podemos constatar que siempre hace lo contrario de lo que cabría esperar. En él, la estilística o la escenografía de la negación no es un contenido; es el modo de producción del contenido» ${ }^{4}$.

Moreau nos ofrece de esta manera su particular acercamiento a la figura de Spinoza, atraído también por sus efectos sorprendentes.

Sea cual sea la cualidad de la relación entre los lectores y Spinoza, me interesa destacar ahora un hecho significativo: esa irresistible fascinación por este filósofo se expresa literariamente con gran frecuencia a través de metáforas lumínicas, incluso cristalinas. Constituye una constante en la historia de la filosofía que el campo semántico de la visión, de la luz, se ha empleado en muchas ocasiones al servicio de la explicación de las teorías del conocimiento. Pues bien, en el caso de Spinoza, además, se configura como un medio extraordinario al permitir que la afectividad de algunos de sus lectores privilegiados resplandezca en contacto con la luz que su obra irradia. Un juego de reflejos, donde cierta opacidad inicial que puede padecer el lector ante las obras de Spinoza, se aclara y se convierte en intensa y afectiva transparencia, más misteriosa aún si cabe.

Veamos esos reflejos a través de algunos textos escogidos de autores tan dispares, como un filósofo, Wilhelm Dilthey, y un literato, Romain Rolland, pero con un elemento común, el hilo luminoso que ambos vieron y sintieron resplandecer en la filosofía de Spinoza, aunque con intensidades e intereses muy distintos: un interés teórico y académico en el caso de Dilthey, una vivencia juvenil de profunda conmoción en el caso de Rolland. Son, por tanto, los breves textos que voy a comentar a continuación bajo ese prisma unificado, y no los nom-

\footnotetext{
${ }^{3}$ Ibidem, p. 14.

${ }^{4}$ Ibídem, p. 15.
} 
bres propios de sus autores con sus especiales interpretaciones, los que han motivado la elaboración de este artículo.

\section{Una feliz metáfora de Dilthey}

El filósofo alemán, Wilhelm Dilthey (1833-1911), cuyos textos han sido precisamente el motor inicial de este escrito, fue uno de los autores más representativos del Historicismo y dedicó su obra al estudio hermenéutico de la filosofía, o a lo que él mismo denominaba «crítica de la razón histórica». Puso todo su empeño en elaborar el método de las ciencias del espíritu (ciencias subjetivas), y otorgarles un estatuto de conocimiento verdadero, teniendo en cuenta que en su época el dominio de las ciencias de la naturaleza (ciencias objetivas) era omnipresente. Su amplísima obra no alcanzó una formulación sistemática, sino que manifestaba más bien cierto carácter fragmentario, pero aportó valiosas intuiciones a través de sus estudios históricos.

Spinoza no fue para Dilthey uno de los autores preferentes, objeto de sus análisis, sino que formó parte de ese elenco amplísimo de nombres que el filósofo alemán rastreó en la obra Weltanschaunng und Analyse des Menschen seit Renaissance und Reformation (1914), correspondiente al segundo volumen de sus obras completas, y cuya versión española, publicada en 1944, apareció bajo el título de Hombre y Mundo en los Siglos XVI y XVII $T^{5}$. Aquí Dilthey pretendía buscar una explicación genética de los sistemas metafísicos a partir de la concepción del hombre en diversas épocas históricas, concretamente, en los siglos XV, XVI y XVII.

Aunque la interpretación que Dilthey nos ofrece de Spinoza en esa obra ha sido criticada y superada por una gran variedad de estudios posteriores, sí que revela un gran conocimiento del autor holandés e interesantes aportaciones, como el estudio que realiza del estoicismo y del naturalismo renacentista y sus

\footnotetext{
${ }^{5}$ Cf. Wilhelm Dilthey, Hombre y Mundo en los Siglos XVI y XVII, FCE, México, 1947 (1ª edición en español: 1944). El traductor y prologuista de esta versión, Eugenio Imaz, explica en el prólogo las modificaciones de esta edición respecto a la alemana: cambio del título original, variación del orden de presentación de algún texto y supresión de algunos ensayos que sí aparecían en la edición alemana.
} 
influencias sobre Spinoza. Vayamos ahora a los dos textos que de esa obra de Dilthey he entresacado, y al enfoque que resaltaré en ellos:

«Cómo de esta masa de ideas de tinte estoico pudo surgir el brillante cristal del sistema spinoziano, con arreglo a qué ley se constituyó, podrá verse una vez que se haya estudiado la relación de Spinoza con el movimiento científico-natural y con Giordano Bruno» ${ }^{6}$.

«Spinoza digiere lo que ha leído y lo convierte en fuerza vital propia. Por tal razón, todas las demostraciones de dependencia directa sirviéndose de paralelos se mueven en límites muy estrechos. Pero el núcleo de sus ideas está inspirado, desde el primer diálogo, por un gran movimiento de la época, sea cualquiera el modo cómo en particular llegó a su conocimiento.

De la relación de su profunda alma con este movimiento ambiente surge la forma interna y la estructura de su sistema. Esto se nos ofrece con tal nitidez lo mismo en la Ética que antes en el fragmento De emendatione y todavía antes en el Tratado, que en este aspecto Spinoza se planta ante nosotros como un cristal transparenter).

Me he permitido subrayar la categoría lumínica común que aparece en los dos textos, «cristal», con sus respectivos adjetivos, «brillante» $\mathrm{y}$ «transparente», adjetivos ambos que, junto al sustantivo común y muy significativo, «cristal», me servirán de hilo conductor en el bifaz interpretativo que quiero destacar aquí.

Ya en esta temprana metáfora de Dilthey que revela una preciosa intuición, la filosofía de Spinoza se configura como geometría cristalina que permite filtrar la luz del conocimiento y de las fuentes de las que se alimenta (estoicos, Telesio, Bruno, Vives, etc.), para reflejar después su propio rayo, el brillante sistema que él creó, de tal manera que su profunda obra transparenta el ambiente espiritual de su época. Esa conjunción de síntesis de ideas de autores anteriores, y de originalidad y profundidad es lo que convierte a la teoría de Spinoza en un cristal compacto, unificado, y en consecuencia, íntegro y muy fuerte, pero también accesible y sensible a los reflejos que otros, los demás, queramos ver en él. La metáfora no es baladí.

Sabemos que las piedras preciosas cristalizan en distintos sistemas geométricos internos que en muchas ocasiones, de modo natural, o artificial mediante

${ }^{6}$ Ibídem, p. 308. (La cursiva es mía).

${ }^{7}$ Ibidem, p. 435. (La cursiva de las tres últimas palabras es mía). 
el tallado, pueden manifestarse en una forma externa, también geométrica. Recordemos que el oficio escogido por el filósofo holandés para ganarse la vida fue el de pulidor de lentes, y a ello hay que añadir su interés por el mundo científico de la óptica. Y ese cristal que constituye la filosofía de Spinoza es además en palabras de Dilthey_ «brillante» y «transparente». Brillante, por la originalidad con la que sintetizó y metabolizó las ideas recibidas para crear algo nuevo. Transparente, porque al mismo tiempo reflejaba ese caudal originario de donde manaban sus ideas. Pero más allá del juego interpretativo de Dilthey entre la detección del espíritu de la época en las obras de Spinoza y la transformación a la que este último sometió dicha cosmovisión, quiero señalar otras dimensiones que alberga, según mi lectura o mi personal reflejo, el campo semántico que nos brinda Dilthey en los textos citados.

Los términos alemanes originales que aparecen respectivamente en los dos párrafos escogidos son en concreto: «der glänzende klargeschliffene Kristall» ${ }^{8}$ (el brillante cristal) y «ein durchsichtiger Kristall ${ }^{9}$ (un cristal transparente). La traducción de Eugenio Imaz en la edición española citada de la obra de Dilthey es correcta, si bien podemos añadir los siguientes matices a fin de enriquecer la interpretación que me está sirviendo de eje en este artículo:

— La expresión «der glänzende klargeschliffene Kristall» se refiere a un cristal resplandeciente o reluciente, bien pulido.

— En cuanto a «durchsichtigen», significa claramente «transparente» o «diáfano», que permite el paso de la luz.

Así, los dos adjetivos en juego irradian dos resonancias marcadas, diversas, pero no necesariamente opuestas. Por un lado, «cristal transparente», que nos permite hacer un guiño al orden del intelecto y su estructura geométrica; y por qué no, a una determinada línea interpretativa, que incide en la inmanencia y su vinculación con la categoría espacial de superficie en la teoría del filósofo. Por otro lado, «brillante cristal», que podemos relacionar con un aspecto más pregnante de la luz, los afectos que despierta en los lectores la filosofía de Spinoza, y además su propia afectividad contenida, pero latente en profundidad, y que también

\footnotetext{
${ }^{8}$ Cf. Dilthey, Gesammelte Schriften II. Weltanschaunng und Analyse des Menschen seit Renaissance und Reformation, Stuttgart, B. G. Teubner Verlagsgesellschaft, 1964 (1ª ed.: 1914), p. 296.

${ }^{9}$ Ibidem, p. 443.
} 
resplandece en nosotros y nos conmueve como los ríos de lava de un volcán. Recordemos la comparación tan conocida que Gilles Deleuze propone acerca de las dos Éticas: la geométrica, que discurre a través de las proposiciones, definiciones, demostraciones, corolarios, y la volcánica disruptiva, que emerge en los escolios $^{10}$; y al fin, según Deleuze, las dos Éticas convergerán en una tercera, aérea, luminosa, la del Libro Quinto ${ }^{11}$. Considero que el amor intelectual de Dios es, precisamente, la fórmula de Spinoza que mejor expresa esta actitud de bifaz prismático que encierran al unísono nuestro conocimiento y nuestra experiencia vital afectiva; gracias a ese tercer género de conocimiento o amor intelectual de Dios, Spinoza trata de integrar razón y afectos avanzando hacia una dimensión cognoscitiva cada vez más amplia y más potente del ser humano.

La riqueza de los reflejos que ofrece el fenómeno Spinoza en intérpretes y lectores ocasionales va más allá de la bifurcación en un doble rayo, sin embargo, esos dos hilos de luz son los que me interesa resaltar ahora. Incluso Michel Henry utilizó una comparación espacial para explicar esa superposición de niveles que revela la complejidad de la filosofía spinoziana y su enganche existencial: a) superficie, referida a la doctrina abstracta, al sistema, b) y profundidad, en relación con la experiencia fundante del filósofo, interpretada por Henry como búsqueda de la felicidad ${ }^{12}$. Por cierto, el propio Henry no es ajeno a la utilización de metáforas cristalinas cuando nos habla del pensamiento milagroso de Spinoza que cristaliza, formando estalactitas ${ }^{13}$.

Anticipo que las connotaciones ya apuntadas de la expresión «cristal transparente» podrían observarse muy bien en la relación borgiana con el filósofo judío. Sin embargo, no es éste un aspecto que vaya a desarrollar en este artículo, por las razones mencionadas al comienzo. En cambio, voy a detenerme en el otro hilo de luz, «brillante cristal», y en los efectos tan intensos que provocó la lectura de la obra de Spinoza en el gran escritor francés, Romain Rolland, relativamente poco conocido en España hasta ahora.

\footnotetext{
${ }^{10}$ Cf. Gilles Deleuze, Spinoza: Filosofía práctica, Barcelona, Tusquets Editores, 1984 (ed. original: Spinoza: philosophie practique, 1970), p. 41.

${ }^{11}$ Cf. Deleuze, «Spinoza y las tres “Éticas”» en Crítica y clínica, Barcelona, Anagrama, 1996 (ed. original: Critique et clinique, 1993), p. 209.

${ }^{12}$ Cf. Michel Henry, La felicidad de Spinoza, Buenos Aires, La Cebra, 2008 (ed. original: Le bonheur de Spinoza, 2004), p. 37.

${ }^{13}$ Ibidem, p. 36.
} 


\section{El relámpago en Romain Rolland}

El premio Nobel francés Romain Rolland (1866-1944) sintió el profundo resplandor de la conciencia al leer en su adolescencia las obras de Spinoza y, en especial, la Ética. Relata la profundidad de ese impacto en un breve escrito, lleno de metáforas luminosas y afectivas de gran belleza, L'éclair de Spinoza, que luego — con algún añadido, donde racionaliza su experiencia— formará parte de su autobiografía, Le voyage intérieur ${ }^{14}$ :

«No olvidaré jamás que, en medio del ciclón de mi adolescencia, encontré mi refugio en el nido profundo de la Ética...» ${ }^{15}$

«Ha bastado una página, la primera, y cuatro definiciones, y algunos destellos de fuego han saltado al choque del sílex de la Éticas ${ }^{16}$.

No sería ésta la única revelación definitiva en su vida. Rolland describe otras dos: la plácida visión de la naturaleza desde la terraza del jardín de la casa de Voltaire en Ferney (Suiza) ${ }^{17}$; y la sensación gozosa de pérdida de límites, de ubicuidad, durante un corto viaje en tren cuando éste se detuvo en medio de un túnel, sensación alucinada que le conectó con algunas palabras de Tolstói en Guerra y paz, donde uno de sus personajes, Pierre, mientras se halla prisionero del ejército francés, ríe feliz al reconocerse vinculado con todo lo que rodea ${ }^{18}$. La lectura de Spinoza será el segundo de esos tres momentos deslumbrantes en la vida de Rolland (Les trois éclairs), y seguramente el más influyente, dada su fuerte conexión intelectual y vital con aquellas «palabras de fuego» ${ }^{19}$ del filósofo holandés. De alguna manera, estos tres relámpagos sumergieron a Rolland en una vivencia intensa y fugaz de conexión con el todo, es decir, con las tres totalidades por excelencia para el ser humano: la naturaleza (Ferney), Dios (Spinoza), la fraternidad universal de la humanidad entera (el túnel y Tolstói). Incluso me atrevo a

${ }^{14}$ Cf. Romain Rolland, Empédocle d'Agrigente. L'éclair de Spinoz̧a, París, Éditions du Sablier, 1931, pp. 105-131. Este escrito concreto sobre Spinoza se halla incluido dentro de Le voyage intérieur (Songe d'une vie), París, Albin Michel, 1959 (edición revisada y aumentada respecto a la edición inicial de 1942), y se integra bajo un epígrafe más amplio, «Les trois éclairs». A partir de ahora, citaré este texto de Rolland según esta edición de 1959.

15 Ibidem, p. 33.

${ }^{16}$ Ibidem, p. 34.

${ }^{17}$ Ibidem, pp. 28-31.

${ }^{18}$ Ibidem, pp. 44-5. 
formular la hipótesis de que el segundo de los momentos (Spinoza) serviría de gozne entre los otros dos, e integraría a posteriori las tres dimensiones sentidas (naturaleza, Dios, humanidad) y los afectos activos concomitantes (paz, amor, alegría). Rolland tuvo la dicha de gozar ese fogonazo spinozista, que llenó sus «venas del fuego que hace latir el corazón del universo» ${ }^{20}$. En estas condensadas palabras emerge la cálida y ferviente afectividad sentida hacia el filósofo holandés, y brota el carácter centelleante de esa iluminación filosófica que Rolland experimentó.

El gran literato francés refiere su acercamiento a la filosofía en el Liceo Louisle-Grand, durante su preparación para entrar en la École Normale Supérieure, de la cual sería alumno de 1886 a 1889: desde las clases que le acercaron a Descartes, y en cuya estela de pensamiento permaneció durante dos o tres años, hasta aquellas que le abrieron al mundo presocrático, experiencia que años después fructificaría en su obra Empédocle d'Agrigente (1918). Pero había que efectuar un salto y franquear los límites de la filosofía cartesiana, y esa perspectiva infinita se la ofreció Spinoza, que le salvó de la dureza vivida en esos años juveniles, entre los 16 y los 18 («dos años trágicos») $)^{21}$.

Rolland describe con mimo la edición concreta de las obras de Spinoza a la que él accedió y que todavía conservaba en el tiempo del escrito autobiográfico que nos ocupa: tres volúmenes de 1872 traducidos por Émile Saisset bajo el título de Oenvres de Spinoza $a^{22}$. La lectura de esa edición se convirtió en los difíciles años de su adolescencia en «elixir de vida eterna $»^{23}$.

${ }^{19}$ Ibidem, p. 28.

${ }^{20}$ Ibidem, p. 28.

${ }^{21}$ Ibidem, p. 32.

${ }^{22}$ Concretamente, los datos de la edición citada por Rolland son los siguientes: «Oeuvres de Spinoza, traduites par Émile Saisset, —avec une introduction critique, — nouvelle édition revue et augmentéeCharpentier, 1872, 3 volumes in-12, cartonés en vert». Ibidem, p. 115. Recordemos los datos de la edición original: Spinoza. Oeuvres, París, Charpentier, 1843, 2 vols. Una nueva edición de tres volúmenes en 1861 incluye el Tratado político que no se encontraba en la primera edición. Cf. Yanis Prélorentzos, «Difusión y recepción del spinozismo en Francia desde 1665 hasta nuestros días» en Spinoza y España, edición preparada por Atilano Domínguez (Actas del Congreso Internacional sobre «Relaciones entre Spinoza y España», 1992, Almagro), Cuenca, Servicio de Publicaciones de la Universidad de Castilla-La Mancha, 1994, pp. 87-105.

${ }^{23}$ Cf. Rolland, op. cit., p. 33. 
Mucho se ha escrito acerca de la fuerza que determinadas influencias pueden ejercer en la etapa juvenil del desarrollo humano, cuando las pasiones emergen cual impulsos desatados: un buen guía, o no tan bueno, un amigo carismático o unos libros descubiertos por azar o quién sabe por qué hilos misteriosos del destino. La literatura es pródiga en novelas de formación (Bildungsromans); recordemos sólo dos ejemplos señeros: Goethe con su Wilhelm Meister, o Herman Hesse con Demian. La psicología moderna con el psicoanálisis al frente desbrozará los entresijos de la búsqueda y formación de la identidad individual en esa complicada etapa de la vida.

Rolland también sufrió la crisis propia de esa edad, y fue un gran amigo suyo y biógrafo extraordinario, Stefan Zweig, quien se encargó de acercarnos la figura de Rolland y los avatares de su vida y de su proceso creador ${ }^{24}$. Zweig había llegado a la obra de Rolland por casualidad: en casa de una escultora en Florencia, empezó a leer L'aube, y su asombro fue tan grande que quiso conocer en persona a aquel escritor excepcional ${ }^{25}$. Una vez en París, Zweig consiguió entablar amistad con él, y esa relación resultó ser —en palabras del propio Zweig, «la más fecunda de mi vida y, en algunos momentos, incluso decisiva» ${ }^{26}$. Con admiración y cariño elegíacos, el escritor austríaco nos cuenta cómo ese espíritu puro, idealista y fecundo que era Rolland irá descubriendo los grandes maestros que iluminarán el camino de su vocación: Shakespeare, Beethoven, Wagner, Víctor Hugo, Tolstói y, ¡cómo no!, Spinoza. Los grandes espíritus son afines y tarde o temprano acaban encontrándose. Zweig no se plantea en esta biografía qué elementos concretos poseían en común Rolland y Spinoza, más allá de esa universal familiaridad del espíritu.

${ }^{24}$ Cf. Stefan Zweig, Romain Rolland. El hombre y la obra, Buenos Aires, Ediciones Imán, 1935. El libro recoge la vida y obra de Rolland, desde la difícil etapa inicial de su producción artística y luego su evolución posterior hasta el año 1925 en esta edición española. (Ed. original: Romain Rolland: der Mann und das Werk, Fráncfort del Meno, Rütten und Loening, 1921). La traducción francesa se publicó en 1929 con un añadido que incluye el periodo que trascurre de 1919 a 1925: Romain Rolland: sa vie, son oeuvre, París, Éditions Pittoresques. En cualquier caso, esta biografía no abarca la vida ni a la obra completas de Rolland, puesto que éste murió en 1944.

${ }^{25}$ Cf. Zweig, El mundo de ayer. Memorias de un europeo, Barcelona, Acantilado, 2001 (ed. original: Die Welt von Gestern. Erinnerungen eines Europäers, 1944), pp. 258-9.

${ }^{26}$ Ibidem, p. 260. Zweig refiere que otras dos amistades cruciales para él fueron Freud y el poeta Emile Verhaeren. 
Pero lo cierto es que había muchas cosas que unían al escritor francés con el insólito filósofo: el espíritu de superación, la defensa de la libertad de conciencia frente a cualquier tipo de imposición externa, el valor de la justicia como exigencia vivencial y no sólo política, la búsqueda de la paz y la concordia entre los hombres; incluso su común constitución física débil no les restó fuerzas para ejercer de pensadores dotados de una gran dosis de convicción y firmeza.

Los dos, a su manera, fueron héroes, reflejo de una gran integridad moral: Spinoza, excomulgado y perseguido, se mantuvo fiel a su deslumbrante visión filosófica, a su proyecto ético y a sus amigos; Rolland, que pasó de una etapa anónima a una de fuertes polémicas y acontecimientos dramáticos, siempre luchando por los ideales más elevados y un sentido universalista del ser humano. Ambos fueron defensores de la democracia, a pesar de sus imperfecciones y avatares que la dejaban maltrecha, vividos con especial intensidad por Rolland en carne propia (las dos guerras mundiales). Rolland, desde su retiro en Ginebra, había colaborado de manera muy activa durante los inicios de la Primera Guerra Mundial al servicio de la Cruz Roja en la sección de correspondencia; su famoso artículo «Au-dessus de la mêlée» (1914), buscando sin éxito la concordia de los intelectuales por encima de los dos bandos enemigos, significó un acto de gran valentía en medio de una Europa enloquecida por el conflicto bélico. Y aunque se mantuviera aislado en Vézelay durante la ocupación alemana de Francia en la Segunda Guerra Mundial, no dejó de oponerse con bríos al nazismo y al fascismo reinantes. El pacifismo activo de Rolland constituye uno de los grandes referentes para la conciencia europea durante esa primera mitad de siglo tan convulsa en nuestro continente, y lideró todo un movimiento en contra de la guerra y del odio, que no sentó nada bien a las corrientes nacionalistas insufladas de un falso patriotismo, tanto en Francia como en Alemania. Todavía hoy siguen resonando las palabras de Zweig, llenas de admiración y gratitud, hacia quien por aquellos años fatídicos de la Primera Guerra Mundial encarnaba como nadie la verdadera conciencia europea:

«Comenzó solo la lucha contra la aberración de millones. Y en ese momento vivía la conciencia europea — desterrada con odio y con sorna de todos los países y corazones-únicamente en su pecho» ${ }^{27}$.

${ }^{27}$ Cf. Zweig, Romain Rolland. El hombre y la obra, op. cit., p. 229. Asimismo de Zweig, para esta referencia, cf. El mundo de ayer. Memorias de un europeo, op. cit., pp. 262 y 337-339. 
Por otro lado, además de las luces, también hay sombras en la evolución del compromiso político de Rolland. Baste simplemente recordar su apoyo a la URSS de Stalin. El análisis de la complejidad de la postura de Rolland y del reconocimiento de sus propios errores ideológicos excede los objetivos del presente artículo $^{28}$. Pero al margen de sus devaneos con la política soviética y con el Partido Comunista Francés, lo cierto es que la obra de Rolland ha de ser estudiada con independencia de las contradicciones personales experimentadas en esa paradójica etapa de los años treinta, desequilibrante y confusa no sólo para él, sino también para muchos intelectuales europeos. Y más allá de todo aquello, hay que valorar el profundo mensaje filosófico que albergan sus escritos: la búsqueda del sentido de la vida a través de valores universales, la fraternidad, la creatividad humana por encima de la muerte y ese anhelo profundo de una comunidad verdadera de espíritus libres ${ }^{29}$. Y esos valores, y no las ambigüedades ideológicas, eran los que conectaban a Rolland con Spinoza.

Ambos perseveraron en ese tono vital fuerte que les permitió dedicarse en cuerpo y alma a su obra y seguir escribiendo hasta el final, anticipado de manera temprana por la enfermedad en el caso del filósofo holandés. En defensa de sus respectivas libertades para pensar y escribir, renunciaron a la vida académica universitaria. Spinoza, que no había participado nunca de ese mundo, declinó la invitación para impartir clases en la Universidad de Heidelberg que a instancias del Elector del Palatinado había recibido por mediación de Johan Ludwig Fabritius, profesor de Teología y consejero del Elector. Rolland, que ya daba clase en la Universidad (de Historia de la música en la Sorbona, y de Historia en la École Normale Supérieure), renunció de modo definitivo en 1912. Nada de esto les impidió a los dos seguir en la brecha de la creatividad, filosófica y literaria, respectivamente, e irradiar su influencia como modelos ejemplares, no exentos de polémica. El éxito mundano de Rolland al ser galardonado con el Premio

${ }^{28}$ Cf. David James Fisher, Romain Rolland and the Politics of Intellectual Engagement, New Brunswick, New Jersey, Transaction Publishers, 2004 (1º ed.: 1988). También cf. Pierre Sipriot, Guerre et paix autour de Romain Rolland, París, Bartillat, 1997. Y cf. Romain Rolland, une oeuvre de paix, París, Publications de la Sorbonne, 2010 (Actas del coloquio de 2008 bajo la dirección de Bernard Duchatelet).

${ }^{29}$ Cf. Bernard Duchatelet, Romain Rolland tel qu'en lui-meme, París, Albin Michel, 2002; «Un nouveau regard sur Romain Rolland», Conferencia pronunciada en la Sorbona el 12 de diciembre de 2002, Etudes Rollandiennes, $n^{\circ}$ 5. Asimismo cf. la revista Europe, $n^{\circ}$ 942, octubre 2007 (Actas de las Jornadas Internacionales Romain Rolland 2004 bajo la dirección de Bernard Duchatelet). 
Nobel de Literatura en 1925, aparentemente no mantiene ningún parangón con la situación de persecución y maldición que vivió Spinoza, sin embargo, el filósofo judío también tuvo «éxito» a su manera: sus amigos no lo defraudaron jamás, no sucumbió al suicidio o a la locura y él, que criticaba la fama pero nos acercaba la idea de eternidad a través del amor intelectual de Dios, alcanzó una resonancia insoslayable en la posteridad, una eternidad espinozista que sigue latiendo una y otra vez, desde las «Luces radicales» del siglo XVIII a la Modernidad, y a nuestra propia época: por ejemplo, en los libertinos, en el Idealismo alemán y en las proyecciones de las ideas políticas de Spinoza y de su doctrina de los afectos en la actualidad. Por otro lado, hay que insistir en que tanto Spinoza como Rolland se encontraron con un entorno hostil y se repusieron frente a los fracasos gracias a un gran coraje: los dos triunfaron a su manera.

Rolland no escogió al azar a ese maestro espiritual, junto a sus otros dos grandes referentes de juventud, Beethoven y Shakespeare. En palabras de Zweig:

«Más tarde descubrió un tercer maestro, el libertador de su fe, Spinoza, cuya obra leyó en una tarde solitaria en el colegio y cuya suave luz espiritual iluminaría para siempre su alma. Siempre los más grandes de la humanidad constituyen sus ejemplos y compañeros» ${ }^{30}$.

Amorosas son estas palabras del amigo, pero prosigamos escuchando a Rolland y su relato apasionado y conmovido del descubrimiento de Spinoza. Es «el camino natural del espíritu» —al cual sigue obediente como un perro a su instinto- el que lo conduce hasta él ${ }^{31}$. Con una fina sensibilidad literaria describe su primera lectura de la Ética, en medio de una habitación fría en el atardecer del invierno. No importaba lo que ocurriera fuera; como dentro de un recinto amurallado, Rolland se sumerge en esa obra, en las líneas negras de ese libro forrado de verde, y gracias a lo que descubre y a lo que siente, su prisión adolescente de angustias descubre una salida:

«Y bajo la fijeza turbada de mi mirada alucinada, he aquí que los barrotes se separan y que surge el sol blanco de la Substancia. Metal en fusión, que

${ }^{30}$ Cf. Zweig, Romain Rolland. El hombre y la obra, op. cit., p. 20.

${ }^{31}$ Cf. Rolland, op. cit., p. 33. 
llena la copa de mis ojos, se vierte dentro de mi ser que él consume; y mi ser, como una fuente, salta en la cuba...» ${ }^{32}$.

Metáforas visuales e ígneas por doquier, afectivas y alquímicas también para acercarnos esa experiencia profunda que tiene lugar en lo más íntimo de su ser y a la que le ha impulsado su propio conatus, como muy bien diría Spinoza. «Mirada alucinada», «sol blanco», «ojos»: lo visual (leído-comprendido) no queda en la mera superficie, sino que se transmuta en su interior, como ocurre en el proceso de individuación del que nos hablará Jung inspirándose en un trasfondo alquímico; el metal, cual acero del intelecto, se funde y se vierte uniendo contrarios (fuego y agua) para que emerja un Rolland nuevo, con bríos y presto a la tarea de su responsabilidad moral por encima del miedo. Ya Deleuze, recogiendo una lúcida impresión de Victor Delbos, había llamado la atención sobre la conjunción de dos elementos (razón rigurosa y afectividad subterránea), que con mayor o menor intensidad de cada uno de ellos, impactan en aquellos que amorosamente se acercan a Spinoza ${ }^{33}$. Incluso es el propio Deleuze quien emplea algunas metáforas rollandianas para explicar la integración spinozista de concepto y vida, que se opera con una velocidad de pensamiento vertiginosa en el último libro de la Ética:

«El libro V es la unidad extensiva extrema, pero porque constituye también la punta intensiva más condensada: ya no hay diferencia alguna entre el concepto y la vida. Pero también en lo que le precede encontramos la composición y el entretejido de los dos componentes - lo que Romain Rolland llamaba "el sol blanco de la sustancia" y las "palabras de fuego de Spinoza"» ${ }^{34}$.

Como vemos, las palabras de Spinoza poseen la virtud de generar chispazos en cascada, que nos llevan de un lector a otro, y a otros más, cobijados bajo el mismo influjo hipnótico. Pero, retornemos a Rolland y fijemos de nuevo la mirada sobre su experiencia.

32 Ibidem, p. 34.

${ }^{33}$ Cf. Deleuze, Spinoza: Filosofía práctica, op. cit., pp. 159-169. Deleuze se refiere al libro de Delbos, Le probléme moral dans la philosophie de Spinoza et dans l'histoire du spinozisme, París, Alcan, 1893.

${ }^{34}$ Cf. Deleuze, Spinoza: Filosofía práctica, op. cit., p. 169. 
¿Qué será lo que descubre Rolland en Spinoza, en concreto en la Ética? Ya hemos comentado que le bastaron apenas cuatro definiciones de la primera página del Libro I que trata sobre Dios (De Deo), para sentir su fuego. Rolland especifica en nota al pie a qué definiciones del comienzo se refiere, y a qué otras proporciones, que resultaron fulgurantes para él: definiciones 3, 4, 5 y 6, además de las chispas arrancadas («étincelles arrachées)) ${ }^{35}$ de las proporciones 15 y 16 del Libro I y el escolio del lema 7 del Libro II.

Curiosamente en las definiciones iniciales de la Ética, el primer término no es Dios, sino que las nociones fundantes de esa obra de Spinoza en este mismo orden de aparición son las siguientes: causa de sí, cosa finita en su género, substancia, atributo, modo, Dios, cosa libre y cosa necesaria, y eternidad. ${ }^{36}$ Así pues, de entre éstas, las que impactan a Rolland son las nociones de sustancia, atributo, modo y Dios. No está nada mal para comenzar un libro de filosofía plantear - como hace Spinoza - con concisión y visión amplia los grandes asuntos del pensamiento humano: el orden de la realidad y la estructura del intelecto a través de la categoría de causalidad, la doble dimensión finitud/infinitud reflejada en las cosas finitas y en Dios (sustancia infinita), respectivamente, y la conexión entre esa sustancia y las cosas concretas expresada en distintos niveles, los atributos y los modos. Prodigio de síntesis geométrica que, a pesar del uso de un estilo seco, nada literario, e incluso pobre por parte de Spinoza ${ }^{37}$, cala en el

${ }^{35}$ Cf. Rolland, op. cit., p. 34.

${ }^{36}$ Cf. Spinoza, E 1Def1-8, pp. 65-9 de la edición de la Ética demostrada según el orden geométrico a cargo de Vidal Peña, Madrid, Tecnos, 2007. (SO 2, 45-6). El paréntesis corresponde a la referencia a la edición de Carl Gebhardt de las obras de Spinoza, Spinoz̨a Opera, 4 vols., Heidelberg, Carl Winters, 1972 (1 $1^{\mathrm{a}}$ ed.: 1925). A partir de ahora, incluiré la referencia a Spinoza Opera (SO) en las citas de sus textos.

${ }^{37}$ Sobre la pobreza del latín de Spinoza, cf. Fokke Akkerman, «La pénurie de mots de Spinoza», Lire et traduire Spinoza, Groupe de Recherches Spinozistes (GRS), Travaux et documents, no 1, París, Presses de l'Université de Paris Sorbonne, 1989, pp. 9-37. Akkerman estudia la influencia de Van den Enden sobre la formación de Spinoza, en concreto, la referida al conocimiento de los clásicos y al interés por el teatro, por ejemplo, Terencio. Según Akkerman, esos ejercicios de imitación de los clásicos le podrían servir a Spinoza para superar una cierta pobreza de vocabulario. Recordemos que las lenguas naturales del filósofo eran el portugués y el castellano, por sus orígenes sefardíes, además del hebreo por su formación. Su holandés no era tan fluido como sus lenguas familiares, y el latín —lengua en la que escribió la mayoría de sus obras - lo aprendió ya tarde en la escuela de Van den Enden. De ahí, ese estilo seco y austero que caracteriza su escritura. Cf. Steven Nadler, Spinoza, Madrid, Acento editorial, 2004 (ed. original: Spinoza, a Life, 1999), pp. 78 y 98-9, y Koenraad Oege Meinsma, Spinoza et son cercle, París, Vrin, 2006 (ed. original: Spinoza en zijn kring, 1896), pp. 294-5. 
joven Rolland. No importa la distancia inmensa en el modo de escribir (Rolland desarrollará un lenguaje de una gran riqueza y sensibilidad musical extraordinaria, aun con sus altibajos y peculiaridades) ${ }^{38}$; el hilo conductor entre el filósofo y el literato será más hondo.

Además de esas definiciones, traigamos a la memoria el resto de las chispas filosóficas extraídas por Rolland del sílex de la Ética, y que él mismo nos acaba de referir, E 1P15, E 1P16 y E 2L7S, respectivamente, aunque él no cite por ahora de modo literal estos textos:

«Todo cuanto es, es en Dios, y sin Dios nada puede ser ni concebirse» ${ }^{39}$. «De la necesidad de la naturaleza divina deben seguirse infinitas cosas de infinitos modos (esto es, todo lo que puede caer bajo un entendimiento infinito) $»^{40}$.

«Por lo dicho, vemos, pues, cómo un individuo compuesto puede ser afectado de muchas maneras, conservando, no obstante, su naturaleza.....Y si continuamos así hasta el infinito, concebimos fácilmente que toda la naturaleza es un solo individuo, cuyas partes — esto es, todos los cuerpos- varían de infinitas maneras, sin cambio alguno del individuo total» ${ }^{41}$.

De este último texto, E 2L7S, y dada su extensión, me he permitido a la hora de citar una selección donde se refleja la nervadura filosófica fundamental de Spinoza que conecta con el escritor francés, y que tiene mucho que ver con el sentido de realidad infinita y su relación con lo finito (los seres humanos), como iré desbrozando.

\footnotetext{
${ }^{38}$ Zweig destaca el modo especial de la escritura de Rolland, a quien no reconoce un estilo narrativo personal como tal, sino impersonal, y que no se caracteriza por un francés clásico ni por una arquitectura estable; a cambio, destaca por su arte en trasponer los ritmos musicales a las piezas escritas: «Ś́lo tiene una genial capacidad de adaptación al ritmo de los acontecimientos y al acorde de la situación. Es la resonancia, la vibración del sentimiento». Cf. Romain Rolland. El hombre y la obra, op. cit., p. 147. Zweig llega a comparar los escritos de su amigo con distintas obras musicales: lieder, preludios, baladas, nocturnos, para referirse en concreto a la obra maestra de Rolland, su Jean-Christophe. Recordemos que Rolland, profundo conocedor de la música, fue profesor de Historia de la música y autor de una biografía fundamental sobre Beethoven, y otra sobre Haendel, amén de sus numerosos escritos sobre la música y los músicos objeto de su devoción, por ejemplo y además de la ya mencionados, Berlioz.

${ }^{39}$ Cf. Spinoza, E 1P15, p. 81 (SO 2, 56).

${ }^{40}$ Ibidem, E 1P16, p. 86 (SO 2, 60).

${ }^{41}$ Ibidem, E 2L7S, p. 149 (SO 2, 101-102).
} 
Entonces, nos seguimos preguntando: ¿qué es lo que a Rolland le seduce de este libro ígneo, la Ética? El incipiente escritor reconoce que no es propiamente la comprensión del sistema filosófico de Spinoza (no pretende hacerse ilusiones acerca de tamaña empresa que deja para otros), aunque es preciso reconocer que las referencias y citas de textos de los escritos del filósofo que añade Rolland a su testimonio revelan una lectura atenta y lúcida, donde intelecto y sentimiento se dan la mano. Incluso él mismo alude después, cuando racionaliza esta experiencia, a las notas que tomó durante dos años (de 1886 a 1888), hasta que llegó a convertir la fórmula spinozista en su propia fórmula de vida y, modelando el Dios de Spinoza, lo hizo suyo para siempre desde un simbólico día victorioso, 11 de abril de $1887^{42}$. Pero lo cierto es que centrado ahora en su prístina lectura del filósofo, Rolland ni siquiera se detiene en los argumentos que aparecen en la introducción a cargo de Saisset de la edición que está leyendo, y que implican, en la interpretación que efectúa de Spinoza, una crítica al panteísmo desde un marcado sesgo espiritualista por parte de Saisset. Incluso Rolland califica esta introducción de Saisset de «honesta y timorata» ${ }^{43}$. En dicha introducción, Saisset realiza una exposición crítica de la teoría de Spinoza y también una refutación del spinozismo ${ }^{44}$. Aunque Rolland no será filósofo de profesión y, por tanto, no entrará en las discusiones académicas en torno al spinozismo en Francia, sino que su percepción se sitúa en la dimensión personal y en sus consecuencias literarias, en cambio, sí resulta pertinente recordar aquí el contexto en el que se enmarca esta edición de las obras de Spinoza.

Émile Saisset (1814-1863) fue un filósofo francés relevante por su labor académica, profesor en Caen y en la Sorbona, y discípulo perteneciente a la escuela de Victor Cousin. Además de la referida edición de las obras de Spinoza, escribió, entre otros títulos, Précurseurs et disciples de Descartes (1861) y su obra de mayor repercusión en Francia, Discours de la philosophie de Leibniz. (1857). La filiación cartesiana y, en último término, leibniziana, de Saisset es clara, y a Spinoza lo encasilla dentro del panteísmo más audaz, que extrae todas las consecuencias, buenas, pero especialmente malas, de Descartes. Saisset se encuadra dentro del movimiento del espiritualismo ecléctico, que difunde a su manera y critica el spinozismo en la Francia del siglo XIX, y cuyo principal representante es Cousin,

\footnotetext{
${ }^{42}$ Cf. Rolland, op. cit., p. 40.

${ }^{43}$ Ibidem, p. 35.

${ }^{44}$ Cf. Prélorentzos, op. cit., p. 92.
} 
seguido por una numerosa estela de discípulos, que ocuparán la docencia universitaria durante más de treinta años ${ }^{45}$. Esta generación de filósofos franceses afronta el estudio de la doctrina de Spinoza como una forma de defenderse ante las acusaciones de panteísmo, ateísmo y materialismo de las que ellos mismos eran objeto por parte de la filosofía clerical católica ${ }^{46}$. De nuevo, nos encontramos al filósofo judío en el centro — sin buscarlo— de encarnizadas polémicas ideológicas, como al fantasma malévolo que hay que destruir por todos los medios; disputas que lo persiguieron en vida (excomunión de la sinagoga, críticas de calvinistas y cartesianos), y prosiguieron después: los debates en torno a los libertinos en el Siglo de las Luces, el Pantheismusstreit en el alborear del Idealismo alemán, y en la época que estamos tratando, en la Francia del siglo XIX, otra vez la alargada sombra de Descartes planea sobre su discípulo más díscolo e incómodo. Los seguidores de Cousin se aprestan a una doble tarea: por un lado, interpretar de otra manera a Spinoza, puesto que no lo consideran ateo; pero, por otro lado, también se afanan en refutarlo desde una crítica racional, dirigida a su método geométrico, del todo contrario a la idea de libertad humana, a la cual ensalzan y consideran como uno de los mayores logros de Descartes. En cualquier caso, sitúan la metafísica spinozista como heredera de la cartesiana —aunque radicalizada en exceso- - y no de las fuentes judías. El cambio de postura de Cousin en este último aspecto reavivará otro frente más en el seno del espiritualismo ecléctico francés, atizado además por la publicación a cargo de Foucher de Careil en 1854 y 1862 de los textos inéditos de Leibniz sobre Spinoza ${ }^{47}$. $\mathrm{Y}$ es precisamente Saisset quien se encarga de criticar a Cousin y poner las cosas

${ }^{45}$ Ibídem, p. 92. Prélorentzos cita una abundante y muy útil bibliografía en su artículo; entre otros referentes y relacionados con el asunto que nos ocupa, merecen destacarse los siguientes: Pierre-François Moreau, «Spinozisme et matérialisme au XIX ${ }^{\mathrm{e}}$ siècle», Raison présente, $\mathrm{n}^{\circ}$ 52, 1979, pp. 85-94, «Spinozisme et panthéisme», Spinoz̧a entre Lumière et Romanticisme (Actas del coloquio de Fontenay-aux-Roses, 1983), Les cabiers de Fontenay, n ${ }^{\text {s }} 36-38,1984$, pp. 207-213, «Spinoza et Victor Cousin», Archivio di filosofia, 1978, pp. 327-331, «Saisset, lecteur de Spinoza», Recherches sur le XVTIe siècle, París, Éditions de CNRS, n 4, 1989, pp. 85-98; Paul Janet, «Le spinozisme en France», Revue philosophique de la France et de l'Étranger, fév. 1882, t. XIII, pp. 109-132; y, por supuesto y desde una visión más general y no centrada exclusivamente en el siglo XIX, los libros ya clásicos en este terreno de Paul Vernière, Spinoza et la pensée française avant la Révolution, París, PUF, 1954, 2 vol. (reed. 1982 en un vol.), y de Pierre Macherey, Avec Spinoza. Études sur la doctrine et l'bistoire du spinozisme, París, PUF, 1992.

${ }^{46}$ Cf. Prélorentzos, op. cit., p. 92.

${ }^{47}$ Ibidem, p. 93. Sobre la repercusión de la publicación de estos escritos de Leibniz en la polémica en torno al panteísmo de Spinoza en el seno del espiritualismo francés y de la escuela de 
en su sitio, tal como él cree fervientemente y se refleja en uno de sus artículos, «La Philosophie des Juifs, Maïmonide et Spinoza» ${ }^{48}$. En este escrito, Saisset critica la interpretación sobre el filósofo judío a cargo de Cousin, el cual, después de haber defendido la conexión cartesiana de Spinoza hasta determinado momento, cambia de postura y proclama los orígenes judíos — vía Maimónides- del panteísmo de Spinoza. Saisset, que curiosamente califica la Ética como una obra «oscura»" ${ }^{49}$, mantiene la influencia cartesiana sobre el Spinoza de la Ética, lo cual no le impide reconocer la resonancia judía (Maimónides como iniciador de la exégesis racional) en su obra de exégesis bíblica, el Tratado teológico-político, aunque matice que Spinoza tampoco está de acuerdo con todos los planteamientos de Maimónides, ya que critica muchos de ellos, e incluso los lleva al límite. Saisset, parafraseando a Leibniz, llega a plantear que «el spinozismo es un cartesianismo corrompido $»^{50}$, y que Spinoza, en virtud de un pensamiento especulativo extremo, sacrificó la filosofía cartesiana y su dimensión espiritualista en el horroroso altar del panteísmo. Nada le detiene a Saisset para arremeter contra el filósofo holandés, incluso se ampara en argumentos ad hominem, y se atreve a dibujarnos a un Spinoza solitario, obsesivo en su pensar abstracto, que se cree en posesión de la verdad y que niega la libertad y el contacto con los demás seres humanos. El debate polémico en torno a Spinoza y al panteísmo adquirirá un nuevo giro gracias a la interpretación de Taine, quien propiciará una interpretación crítica y positiva del spinozismo, alejada, al fin, de las redes del panteísmo ${ }^{51}$.

Una vez planteado este excurso con el fin de acercarnos de modo somero a la atmósfera filosófica en la Francia del XIX en torno al spinozismo, retornemos a Rolland y a su personal modo de leer los escritos de Spinoza.

Cousin, cf. Moreau, «Les enjeux de la publication en France des papiers de Leibniz sur Spinoza», Révue de Métaphysique et de Morale, $\mathrm{n}^{\circ}$ 2, 1998, pp. 215-222, además de los artículos de Moreau citados en la nota al pie $\mathrm{n}^{\circ}$ 45. Los textos en concreto de Foucher de Careil son los siguientes: Réfutation inédite de Spinoza par Leibniz (précedée d'un mémoire de Foucher de Careil), 1854, y Leibniz, Descartes et Spinoza, 1862.

${ }^{48}$ Cf. Saisset, «La Philosophie des Juifs, Maïmonide et Spinoza», Révue des Deux Mondes, 2 période, tome 37, 1862, pp. 226-334.

${ }^{49}$ Ibidem, p. 315.

${ }^{50}$ Ibídem, p. 327.

${ }^{51}$ Cf. Prélorentzos, op. cit., p. 93. Prélorentzos recoge algunas de las principales ideas de Moreau en su artículo «Taine lecteur de Spinoza», Revne philosophique de la France et de l'etranger, nº 4, 1987, pp. 477-489. 
Los argumentos que esgrime el espiritualista Saisset en la introducción a las obras del filósofo judío no parecen importar a Rolland, y por eso, el incipiente escritor salta por encima de esa pantalla («garde-feu» $)^{52}$ que interpone Saisset y se lanza al corazón mismo de la obra, a esa hoguera («brasien») $)^{53}$ que constituye la Ética. Y entonces, lo que deslumbra a Rolland es otra cosa, un gran descubrimiento:

«...así, en el texto mismo de Spinoza, no le descubrí a él, todavía ignorado por mí. En la inscripción trazada en el portal de la Ética, en esas definiciones de letras flamantes, descifré, no lo que él había dicho, sino lo que yo quería decir, las palabras que mi propio pensamiento de niño, de su lengua inarticulada, se afanaba por deletrear. Jamás se lee un libro. Se lee a través de los libros, sea para descubrirse, sea para controlarse. Y los más objetivos son los más ilusionados. El libro más grande no es aquél cuyo comunicado se imprime en el cerebro, igual que sobre el rodillo de papel un mensaje telegráfico, sino aquél cuyo choque vital despierta otras vidas, y, de una a otra, propaga su fuego que se alimenta de esencias diversas y, convertido en incendio, de bosque en bosque salta» ${ }^{54}$.

Y de nuevo, nos topamos con abundancia de metáforas lumínicas y, específicamente, ígneas. Rolland se descubre a sí mismo cuando se mira en el cristal brillante y bien pulido de la obra de Spinoza. Por eso, el autor francés no se lanza a explicar «el sentido liberador del verdadero pensamiento» ${ }^{55}$ del filósofo; desde luego que no le conquista a Rolland el orden geométrico de la Ética ni su racionalismo, aunque experimente cierto disfrute estético ante los juegos racionales. En cambio, lo que nos ofrece en este breve escrito confesional es ese encuentro con aquello que él buscaba a tientas («à tâtons») ${ }^{56}$ desde niño: el fogonazo de la realidad misma plasmado esta vez en un Spinoza realista, curiosamente olvidado, incluso tapado, por los filósofos de profesión. Reverbera aquí una severa crítica de Rolland a la jerga filosófica: «el pesado verbalismo intelectualı ${ }^{57}$. Y hasta él se extraña de que a esos filósofos académicos no les haya bas-

${ }^{52}$ Cf. Rolland, op. cit., p. 35.

${ }^{53}$ Ibidem, p. 35.

${ }^{54}$ Ibidem, p. 35.

${ }^{55}$ Ibidem, p. 35.

${ }^{56}$ Ibidem, p. 35.

${ }^{57}$ Ibidem, p. 35. 
tado una primera mirada («prémier regard») ${ }^{58}$ para captar el sentido de Realidad — con mayúsculas - que nos trasmite Spinoza. No parece improcedente entresacar de estas líneas una punzada contra un determinado ambiente filosófico de disputas, en cierto sentido sectarias, y más, desde una persona apasionada como Rolland, profundamente conmovido en su afectividad ante los problemas de la humanidad, más que ante las diatribas del intelecto, aunque respetara y valorara siempre las aportaciones filosóficas de sus coetáneos. El realismo «visionario» ${ }^{59}$ que capta Rolland en Spinoza se transparenta en breves textos o fulgores que él mismo transcribe del Tratado de la reforma del entendimiento (TIE), de algunas cartas y, por supuesto, de la Ética. Revisemos los fragmentos en cuestión que recoge Rolland y sus propios comentarios.

En primer lugar, el concepto de realidad que se refleja en el TIE:

«Por donde podemos ver que nos es, ante todo, necesario deducir siempre todas nuestras ideas a partir de cosas físicas o de seres reales, avanzando, en lo posible, siguiendo la serie de las causas, de un ser real a otro ser real, y de forma que no pasemos a lo abstracto y universal, ni para deducir de éstos algo real, ni para deducir de lo real algo abstracto. Ambas cosas, en efecto, interrumpen el verdadero progreso del entendimiento» ${ }^{60}$.

Texto al cual Rolland añade a continuación la argumentación con la que prosigue Spinoza:

«Debo señalar, sin embargo, que por serie de causas y seres reales no entiendo aquí la serie de las cosas singulares y mudables, sino únicamente la serie de las cosas fijas y eternas» ${ }^{61}$.

Rolland enlaza en nota al pie este planteamiento con la definición de realidad que el propio Spinoza ofrece en la Ética: «Por realidad entiendo lo mis-

${ }^{58}$ Ibidem, p. 35.

${ }^{59}$ Ibidem, p. 36.

${ }^{60} \mathrm{Cf}$. Spinoza, Tratado de la reforma del entendimiento, en Tratado de la reforma del entendimiento. Principios de filosofía de Descartes. Pensamientos metafísicos, Madrid, Alianza, 1988. Traducción española de Atilano Domínguez. TIE, 99, pp. 117-8 (SO 2,36). El texto literal que transcribe Rolland en francés se encuentra en la edición de Saisset en p. 338.

${ }^{61}$ Ibídem, TIE, 100, p. 118 (SO 2, 36). Edición de Saisset, p. 338. 
mo que por perfección ${ }^{62}$. Ya sabemos que a Rolland no le interesa una discusión filosófica en torno a conceptos metafísicos, sino que pretende destacar su vivencia espiritual del sentido profundo de la realidad que él cree ver reflejado en las palabras de Spinoza. De ahí que resalte la idea del filósofo en la que se condensa su propio sentir, según su personal apreciación: las cosas fijas y eternas son reales, es más, constituyen lo más real, y de esta forma lo real es lo individual, lo particular ${ }^{63}$. Spinoza, en esta parte del TIE a la que se refiere Rolland, trata de la idea verdadera y de sus diferencias con las demás percepciones, lo cual le lleva a criticar la abstracción ${ }^{64}$. Rolland, manifestando su acuerdo con esa crítica, se asoma al «vértigo» que le produce esa concepción spinozista del Ser único, infinito, real, que es la Substancia ${ }^{65}$. Y dejando a un lado dialécticas especulativas, retoma el misterio sagrado de aquella experiencia de juventud.

Gracias a Spinoza bebe el «vino de fuego» que le catapulta fuera de su «prisión ${ }^{66}$, de ese gran dolor y desesperación sentidos, cual si de una pasión de Cristo se tratara. Las metáforas que emplea Rolland para describir lo terrible de aquellos años de incertidumbres nos acercan mucho al fenómeno religioso de la pasión, como tránsito o noche oscura necesaria para acceder a la iluminación o a la liberación, aunque él mismo no haga una referencia directa a Cristo. Así, por ejemplo: «alas quebradas», «gritos de pasión», «las magulladuras y las lágrimas de sangre» $\rangle^{67}$. Y al fin, el joven Rolland encuentra en Spinoza la respuesta radiante («rayonnante») «al enigma de la Esfinge» ${ }^{68}$ que pesa sobre sus espaldas, en sus propias palabras: «a la antinomia aplastante entre la inmensidad de mi ser interior y el calabozo de mi persona, que me humilla y que me asfixia» ${ }^{69}$.

Y la respuesta irradia desde la Substancia infinita, el Dios de Spinoza, entendido por Rolland — con sabor panteísta — como una inmensidad abarcadora de

\footnotetext{
${ }^{62}$ Cf. Spinoza, E 2Def6, p. 127 (SO 2, 85). En el caso de la Ética, Rolland no cita la paginación de la edición de Saisset.

${ }^{63}$ Cf. Rolland, op. cit., p. 36.

${ }^{64}$ Cf. Spinoza, TIE 75 y 76, pp. 107-8 (SO 2, 28-29).

${ }^{65}$ Cf. Rolland, op. cit., p. 36.

${ }^{66} \mathrm{Ibidem}$, p. 36.

${ }^{67}$ Ibidem, p. 36.

${ }^{68}$ Ibidem, p. 36.

${ }^{69}$ Ibidem, p. 36.
} 
toda la realidad, que se despliega en distintos niveles, según los conceptos que se recogen en la Ética: la «Naturaleza naturante» (atributos de Dios) y la «Naturaleza naturada» (modos de los atributos $)^{70}$. Y el broche de oro de esta visión infinita y liberadora, que ya había anunciado Rolland al comienzo de este escrito y que ahora sí transcribe, se graba con palabras doradas en la Proposición 15 del Libro Primero de la Ética: «Todo cuanto es, es en Dios, y sin Dios nada puede ser ni concebirse» ${ }^{71}$. En medio de una «habitación helada», en una «noche de invierno», Rolland se evade hacia «el abismo de la Substancia», a ese «sol blanco del Ser» ${ }^{72}$. Y en ese momento experimenta su especial iluminación que, no cabe duda, adquiere en él un carácter sagrado, puesto que se halla investida de una sensibilidad mística: «Y yo también, yo soy en Dios» ${ }^{73}$.

Rolland describe ese espacio abierto, descubierto gracias a Spinoza, recurriendo a las metáforas del viaje pionero, del vuelo libre y de la inmersión oceánica, expresiones, todas ellas, frecuentes en los escritos místicos. Esos «horizontes inauditos $\rangle^{74}$ sobrepasan con creces lo soñado por él mismo, y los atributos del pensamiento y la extensión se convierten en «mares sin riberas» que le conducen a su vez a «otros mares desconocidos», los otros atributos infinitos de la substancia y desconocidos; de tal manera que todos los atributos se contienen en «el Océano del Ser» ${ }^{75}$. Ya aquí se transparenta, de alguna manera, el significado de sensación oceánica o sentimiento oceánico, expresiones ambas que Rolland utilizará en una carta a Freud para describir el sentimiento religioso espontáneo del ser humano, al margen de las iglesias, y el suyo propio. Esas matizaciones de Rolland tendrán un profundo impacto en el psiquiatra austríaco. Y de nuevo, los resplandores en cascada nos conducen de un autor a otro, y resulta necesario tratar, aunque con brevedad, la conexión de Rolland con Freud.

La relación de estos dos autores vía epistolar, puesto que sólo se encontraron en una ocasión en la casa vienesa de Freud y ante la presencia de un amigo común, Stefan Zweig, constituye un episodio apasionante de la historia del psi-

\footnotetext{
${ }^{70}$ Cf. Spinoza, E 1P29S, p. 100 (SO 2, 71).

${ }^{71}$ Ibidem, E 1P15, p. 81 (SO 2, 56).

${ }^{72}$ Cf. Rolland, op. cit., p. 36.

${ }^{73}$ Ibidem, p. 36.

${ }^{74}$ Ibidem, p. 37.

75 Ibidem, p. 37.
} 
coanálisis $^{76}$. Además, hay que considerar que el vínculo de ambos con Spinoza, aunque de muy distinta forma en cada uno, aparece como hilo conductor latente de esa comunicación tan fructífera para el proceso creador de los dos ${ }^{77}$. El especialista Henri Vermorel analiza esta relación a tres bandas, Rolland-FreudSpinoza, a la luz de una veintena de cartas que se intercambiaron los dos primeros entre 1923 y 1936, y de su único encuentro el 14 de mayo de 1924. Ese encuentro resultó crucial, puesto que desató tanto en Freud como en Rolland una relación transferencial recíproca muy fecunda que motivaría en Freud su libro, El porvenir de una ilusión, y en Rolland el comienzo de la redacción de su obra confesional, Le voyage intérieur ${ }^{78}$. Vermorel destaca cómo, curiosamente, y a raíz de esta entrevista intensa, Rolland rememora poco tiempo después (entre el 5 y el 20 de julio de 1924) su experiencia juvenil de la lectura de Spinoza mediante su escrito L'éclair de Spinoza, ${ }^{79}$ que — como ya he explicado— incluye en su autobiografía. ¿Casualidades, sincronicidades junguianas, o causalidades spinozistas?

La carta en cuestión de Rolland que me interesa recuperar ahora lleva fecha de 5 de diciembre de 1927. Recordemos que L'éclair de Spinoza (redactado en 1924, como acabo de comentar) fue publicado por primera vez en 1926 en una revista de Asia y en lengua bengalí, tal y como nos lo explica el propio Rolland en nota al pie al comienzo de su escrito en la edición de 1931 ya citada ${ }^{80}$. En esa carta que Rolland dirige a Freud como respuesta a la recepción del libro de este último, El porvenir de una ilusión, se halla de por medio la cuestión religiosa ${ }^{81}$. Las

${ }^{76}$ Cf. Henri Vermorel, «Présence de Spinoza dans les échanges entre Romain Rolland et Sigmund Freud», Conferencia pronunciada en la Sorbona, el 31 de mayo de 2007, Études Rollandiennes, $\mathrm{n}^{\mathrm{o}}$ 18. Sobre la correspondencia Freud-Rolland, cf. Henri Vermorel y Madeleine Vermorel, Sigmund Freud et Romain Rolland. Correspondence 1923-1936, París, PUF, 1993.

${ }^{77}$ Cf. Henri Vermorel, «Présence de Spinoza dans les échanges entre Romain Rolland et Sigmund Freud», op. cit.

${ }^{78}$ Ibidem, pp. $10-12$.

${ }^{79}$ Ibidem, pp. 5, 11-12.

${ }^{80}$ Cf. Rolland, Empédocle d'Agrigente. L'éclair de Spinoz̧a, op. cit., pp. 107-8.

${ }^{81}$ Sobre la relación Rolland-Freud y la importancia del sentimiento oceánico, además de Vermorel, cf. Roger Dadoun, «Rolland, Freud et la sensation océanique», Revue d'bistoire littéraire de la France, $\mathrm{n}^{\circ}$ 76, 1976, pp. 936-946, y «Singulières psychanalyses de Romain Rolland. L'Océanique, l'Abyssal et le Matriciel», Études Rollandiennes, n 14, 2006; y David James Fisher, «Sigmund Freud et Romain Rolland: l'animal terrestre et son grand ami océanique», Topique, n 18, 1976, pp. 117 155. 
palabras de Rolland para referirse al sentimiento religioso espontáneo son las siguientes:

«...el hecho simple y directo de la sensación de lo eterno [...] sin límites perceptibles y como oceánica».

«Yo mismo estoy familiarizado con esta sensación [...] y en ella siempre he encontrado una fuente de renovación vital».

«...llevo simultáneamente [...] una vida "religiosa" en el sentido de esta sensación prolongada y una vida de razón crítica (que es sin ilusión) $\rangle^{82}$.

Sabemos que esta experiencia de inmersión en lo infinito presente a lo largo de la vida de Rolland tiene su origen en su adolescencia y en esos tres resplandores que él mismo ha aglutinado bajo el mismo y común denominador. Incluso, en uno de sus escritos juveniles, Creo quia verum (1888) ya menciona, bajo el influjo de lo que denomina «Spinozismo de la Sensación cerebral» ${ }^{83}$, esa sensación oceánica de sumergirse en $\operatorname{Dios}^{84}$. Y años después, profundizará en ese sentimiento gracias a sus estudios sobre los místicos hindúes y las biografías de Ramakrishna y de Vivekananda, además de su acercamiento personal a Tagore y a Gandhi ${ }^{85}$. Aunque Rolland perdiera su fe católica en la adolescencia - y en ese sentido compartiera con Freud la crítica a «las iglesias»—, en cambio — y a diferencia de Freud-, su sentimiento espiritual profundo permanece vivo y constante en medio de los avatares vividos. Y la lectura de las obras de Spinoza, su denodado esfuerzo en aquellos años de juventud temprana por «incor-

${ }^{82}$ Cf. H. Vermorel, «Présence de Spinoza dans les échanges entre Romain Rolland et Sigmund Freud», op. cit., p. 16. Vermorel escoge estos fragmentos de la carta de Rolland a Freud para resaltar la influencia que alcanzará en el padre del psicoanálisis esta experiencia acerca de la sensación oceánica que le relata Rolland. R. Dadoun analiza más en detalle esta carta de Rolland a Freud, y recoge además otro de sus fragmentos, donde Rolland emplea también la expresión «sentimiento oceánico» para referirse a esa estructura mental universal que sería «la verdadera fuente subterránea de la energía religiosa»; según Dadoun, la expresión «sentimiento oceánico» prevalece sobre la de «sensación oceánica», ya que esta última tendría una connotación más orgánica: cf. «Singulières psychanalyses de Romain Rolland. L'Océanique, l’Abyssal et le Matriciel», op. cit., pp. 10-11.

${ }^{83}$ Cf. Rolland, Le voyage intérieur (Songe d'une vie), op. cit., p. 40.

${ }^{84}$ Cf. H. Vermorel, «Présence de Spinoza dans les échanges entre Romain Rolland et Sigmund Freud», op. cit., p. 5.

${ }^{85}$ Cf. Rolland, Mahatma Gandhi, París, Stock, 1924, Éssai sur la mystique et l'action de l'Inde vivante. La vie de Ramakrishna, París, Stock, 1929, Essai sur la mystique et l'action de l'Inde vivante. La vie de Vivekananda et l'Évangile universel, París, Stock, 1930. 
porar el Verbo revelador» ${ }^{86}$ del filósofo, resultan un lugar privilegiado de esa experiencia fundante para Rolland sobre el sentido de la existencia. Retomemos el relato sobre «las palabras de fuego de Spinoza» en su parte final, donde el escritor francés culmina su particular visión de esa filosofía.

Rolland percibe a Spinoza como un pionero de la ciencia moderna al plantear la intuición de los infinitos atributos que abren el universo y lo enriquecen, produciendo en Rolland «la embriaguez de la certeza» ${ }^{87}$ de su existencia, un profundo pálpito y no sólo un conocimiento racional: «La intuición de Spinoza abre los cielos cerrados, avanzando dos siglos, pionera de los conquistadores de la ciencia moderna» ${ }^{88}$.

Esa vivencia de Rolland se refleja en sensaciones físicas: el corazón y el pecho expandidos, la respiración amplia y profunda, soplo a soplo («soufflé à soufflé»)), la mirada fija, sin parpadeos. Sensaciones físicas que se dan al unísono de la intuición liberadora disfrutada por Rolland: la expansión de su espíritu a la luz del resplandor del rostro de la totalidad, y la certeza de sentirse protegido, «sostenido por la infalible mano de la Libre Necesidad que emana de Dios» ${ }^{90}$. Precisamente aquí Rolland se hace eco de una carta que Spinoza escribe a Schuller, donde el filósofo trata el problema de la libertad, critica el planteamiento cartesiano y defiende la idea de necesidad libre, frente al concepto tradicional de libre albedrío ${ }^{91}$. Y también recurre Rolland a otra de las cartas de Spinoza, esta vez dirigida a Oldenburg, en la cual — tratando las objeciones que Oldenburg le había enviado referidas a tres proposiciones-, el filósofo concluye lo siguiente acerca de uno de los atributos, la extensión: «...si se aniquilara una parte de la materia, se desvanecería simultáneamente toda la extensión» ${ }^{92}$. Ese sentido de pertenencia a algo más grande que uno mismo y de permanencia en la eternidad

${ }^{86}$ Cf. Rolland, Le voyage intérieur (Songe d'une vie), op. cit., p. 40.

${ }^{87}$ Ibidem, p. 37.

${ }^{88}$ Ibidem, p. 37.

${ }^{89}$ Ibidem, p. 37.

${ }^{90}$ Ibidem, p. 37.

${ }^{91}$ Cf. Spinoza, Ep 58, pp. 335-229, en Correspondencia, Madrid, Alianza, 1988 (edición de Atilano Domínguez). (SO 4, 265-8). Rolland refiere esta carta con número 44, puesto que se basa en la edición de Saisset.

${ }^{92}$ Ibidem, Ep 4, p. 89, en Correspondencia, op. cit. (SO 4, 14). En este caso, la referencia numérica de la carta que nos ofrece Rolland es la misma. 
conmueve en lo más profundo al incipiente escritor, y al fin, su prisión individual y la torturante culpabilidad que conllevaba se desvanecen en el seno del universo entero, y advienen la calma, la armonía, la plenitud. Y así Rolland enlaza con las palabras sublimes del final de la Ética de Spinoza, con la beatitud, la felicidad, la salvación o liberación emanadas del tercer género de conocimiento, el amor intelectual de Dios:

«El sabio, por el contrario, considerado en cuanto tal, apenas experimenta conmociones del ánimo, sino que, consciente de sí mismo, de Dios y de las cosas con arreglo a una cierta necesidad eterna, nunca deja de ser, sino que siempre posee el verdadero contento del ánimo» ${ }^{93}$.

La captación de este mensaje no la efectúa Rolland «con los ojos fríos de la inteligencia», sino con «la pasión de su corazón y el ardor de sus sentidos» ${ }^{94}$, captación tan intensa que suscita en él un sentimiento de veneración a Spinoza, al cual califica como «nuestro Krishna de Europa» ${ }^{95}$, y es él quien le lleva a saborear la eternidad, el infinito, en clara referencia a una célebre carta de Spinoza a Meyer (carta muy extensa donde precisamente se trata, entre otros, el problema del infinito $)^{96}$. La cita completa en esta carta de Spinoza que Rolland recoge de modo parcial del latín original es la siguiente:

«De aquí se deriva la diferencia entre la eternidad y la duración. Pues por la duración sólo podemos explicar la existencia de los modos, mientras que la existencia de la sustancia se explica por la fruición infinita de existir o, forzando el latín, de ser» ${ }^{97}$.

La descripción de Rolland se halla llena de metáforas sensitivas para referirse a este proceso existencial gozoso («essendi fruitio») cuando siente las palabras

\footnotetext{
${ }^{93}$ Cf. Spinoza, E 5P42S, p. 417 (SO 2, 308).

${ }^{94}$ Cf. Rolland, Le voyage intérieur (Songe d'une vie), op. cit., p. 37.

${ }^{95}$ Ibidem, p. 38.

${ }^{96}$ Cf. Spinoza, Ep 12, en Correspondencia, op. cit., pp. 129-136 (SO 4, 52-62).

${ }^{97}$ Ibidem, Ep 12, en Correspondencia, op. cit., p. 131. La traducción de Domínguez da por sobreentendida la vinculación de substancia infinita y eternidad; sin embargo, en el texto literal, el término «eternidad» aparece repetido al final de la frase en cuestión. Lo anoto aquí a fin de evitar cualquier ambigüedad y realzar el significado de esta correlación: «Substantiae vero per Aeternitatem, hoc est, infinitam existendi, sive, invita latinitate, essendi fruitionem». (SO 4, 55).
} 
del «latín bárbaro» del filósofo y alcanza la unión de razón y sentimiento en armonía: «sabor sensual», «mis ojos», «mis manos», «mi lengua», «los poros de mi pensamiento», «he abrazado al Ser» ${ }^{98}$. Incluso Rolland hace un guiño al Zaratustra de Nietzsche al considerar a Spinoza como un precursor - incluso superior al propio Nietzsche - de esa captación alegre, potente y gozosa de la existencia ${ }^{99}$, que también resuena en los acordes de la Novena Sinfonía de Beethoven. Y Rolland se apresta a extraer algunas perlas vitalistas de los textos de Spinoza, donde se ensalza la alegría gracias a un sano realismo alejado de ascetismos mortificantes, y se insta a la unión entre los hombres:

«La alegría [...] es un afecto que aumenta o favorece la potencia de obrar del cuerpo; $[. .$.$] y así [\ldots]$ la alegría es directamente buena, $[\ldots]\rangle^{100}$

«El regocijo no puede tener exceso, sino que es siempre bueno $[\ldots]\rangle^{101}$

«Pues la risa, [...] es pura alegría y, por tanto, con tal que no tenga exceso, es de por sí buena $[\ldots]{ }^{102}$

«...es propio de un hombre sabio reponer fuerzas y recrearse con alimentos y bebidas agradables, tomados con moderación, así como gustar de los perfumes, el encanto de las plantas verdeantes, el ornato, la música, los juegos que sirven como ejercicio físico, el teatro y otras cosas por el estilo, de que todos pueden servirse sin perjuicio alguno» ${ }^{103}$

«Lo que lleva a la consecución de la sociedad común de los hombres, o sea, lo que hace que los hombres vivan en concordia, es útil,...» ${ }^{104}$.

La música sublime de Beethoven y los versos de Schiller acompañan ese instante sagrado vivido en su adolescencia: «Seid umschlungen, Millionen!...»Y Ye esta manera, con su apoteósica «oda a la alegría» spinozista, reflejada en un maravilloso sentimiento de pertenencia y fraternidad universales, concluye Rolland el relato de la brillante iluminación sentida gracias al fuego del latín áspero de Spinoza.

\footnotetext{
${ }^{98}$ Cf. Rolland, Le voyage intérieur (Songe d'une vie), op. cit., p. 38.

${ }^{99}$ Ibidem, p. 38.

${ }^{100}$ Cf. Spinoza, E 4P41D, p. 331 (SO 2, 241).

${ }^{101}$ Ibidem, E 4P42, p. 331 (SO 2, 241).

${ }^{102}$ Ibidem, E 4P45S, p. 335 (SO 2, 244).

${ }^{103}$ Ibidem, E 4P45S, p. 335 (SO 2, 244).

${ }^{104}$ Ibidem, E 4P40, p. 331 (SO 2, 241).
} 


\section{Conclusiones}

El sorprendente impacto de la filosofía de Spinoza sobre diversos autores (filósofos, literatos, científicos, etc.) se manifiesta en muchas ocasiones a través de una gran admiración, fruto de una fuerte vinculación afectiva con sus ideas o con su figura. La expresión de esa admiración suele abundar en metáforas cristalinas, vinculadas al campo semántico visual.

Considero que una temprana y sugerente metáfora de Dilthey, en la que este asemeja la filosofía de Spinoza con un cristal brillante y transparente, sirve a la perfección para enfocar esa atracción hipnótica que ejerce el filósofo holandés. La presencia de la racionalidad geométrica de su sistema ("cristal transparente») y también la afectividad latente («brillante cristal»), oculta tras el aparato geométrico y que posibilita la resonancia afectiva en sus lectores, constituyen algunas de las razones del embrujo de Spinoza.

Un caso paradigmático del efecto fulgurante de ese brillante cristal filosófico es el escrito de Romain Rolland, L'éclair de Spinoza. El encuentro con las obras del filósofo resulta crucial para Rolland durante la crisis de su adolescencia, y supone un potente catalizador de su propia evolución espiritual, como se reflejará después en su relación con Freud. El escritor francés expresa la fuerza e intensidad de esa iluminación a través de categorías lumínicas, ígneas. Los ejes que articulan esa chispeante conexión afectiva de Rolland con Spinoza son la captación del carácter de eternidad de la realidad (la sensación oceánica experimentada al sumergirse en la substancia spinozista) y la vivencia de intensa alegría y liberación que le produce el sentimiento de fraternidad universal, sentimiento que enlaza con la idea de afinidad, presente también en la comunidad de hombres libres que anhelaba Spinoza.

De esta manera, el latido del pensar spinoziano ha seguido vivo a pesar de sus detractores, y una prueba de ello es su radiante presencia a través de Romain Rolland, uno de los escritores franceses de mayor prestigio e influencia en la conciencia europea durante la primera mitad del siglo XX. 


\section{Bibliografía}

Akkerman, F. (1989). «La pénurie de mots de Spinoza», Lire et traduire Spinoza, Groupe de Recherches Spinozistes (GRS), Travaux et documents, $n^{\circ} 1$, París, Presses de l’Université de Paris Sorbonne, pp. 9-37.

Dadoun, R. (1976). «Rolland, Freud et la sensation océanique», Revue d'bistoire littéraire de la France, $\mathrm{n}^{\circ} 76$, pp. 936-946.

- (2006). «Singulières psychanalyses de Romain Rolland. L'Océanique, l’Abyssal, le Matriciel», Conferencia pronunciada en la Sorbona el 19 de enero de 2006, Études Rollandiennes, $\mathrm{n}^{\mathrm{o}} 14$.

Deleuze, G. (1984). Spinoza: Filosofía práctica, Barcelona, Tusquets Editores, (ed. original: Spinoza: philosophie practique, 1970).

— (1996). «Spinoza y las tres "Éticas"», en Crítica y clínica, Barcelona, Anagrama, (ed. original: Critique et clinique, 1993).

DiLthey, W. (1947). Hombre y Mundo en los Siglos XVI y XVII, México, FCE, (1 a edición en español: 1944).

- (1964). Gesammelte Schriften II. Weltanschaunng und Analyse des Menschen seit Renaissance und Reformation, Stuttgart, B. G. Teubner Verlagsgesellschaft, (1 ${ }^{\mathrm{a}} \mathrm{ed} .:$ 1914).

Duchatelet, B. (2002). Romain Rolland tel qu'en lui-meme, París, Albin Michel.

- (2002). «Un nouveau regard sur Romain Rolland», Conferencia pronunciada en la Sorbona el 12 de diciembre de 2002, Études Rollandiennes, $\mathrm{n}^{\circ} 5$.

- (2007). Europe, $n^{\circ}$ 942, (Actas de las Jornadas Internacionales Romain Rolland 2004 bajo la dirección de Bernard Duchatelet).

- (2010). Romain Rolland, une oeuvre de paix, París, Publications de la Sorbonne (Actas del coloquio de 2008 bajo la dirección de Bernard Duchatelet).

Fisher, D. J. (1976). «Sigmund Freud et Romain Rolland: l'animal terrestre et son grand ami océanique», Topique, $\mathrm{n}^{\circ}$ 18, pp. 117-155.

- (2004). Romain Rolland and the Politics of Intellectual Engagement, New Brunswick, New Jersey, Transaction Publishers (1º ed.: 1988).

Henry, M. (2008). La felicidad de Spinoza, Buenos Aires, La Cebra, (ed. original: Le bonheur de Spinoza, 2004).

Macherey, P. (1992). Avec Spinoza. Études sur la doctrine et l'bistoire du spinozisme, París, PUF. 
Meinsma, K. O. (2006). Spinoza et son cercle, París, Vrin (ed. original: Spinoza en zijn kring, 1896).

Moreau, P.-F. (1978). «Spinoza et Victor Cousin», Archivio di filosofia, pp. 327-331.

- (1979). «Spinozisme et matérialisme au XIX siècle», Raison présente, n 52, pp. 85-94.

- (1984). «Spinozisme et panthéisme», Spinoza entre Lumière et Romanticisme (Actas del coloquio de Fontenay-aux-Roses, 1983), Les cabiers de Fontenay, n ${ }^{\text {os }} 36-38$, pp. $207-$ 213.

- (1989). «Saisset, lecteur de Spinoza», Recherches sur le XVIIe siècle, París, Éditions de CNRS, no 4, pp. 85-98.

- (2004). «نPor qué fascina Spinoza a los escritores?», Cuadernos del Seminario Spinoza, $\mathrm{n}^{\circ}$ 18.

NAdler, S. (2004). Spinoza, Madrid, Acento editorial (ed. original: Spinoza, a Life, 1999).

Prélorentzos, Y. (1994). «Difusión y recepción del spinozismo en Francia desde 1665 hasta nuestros días», Spinoza y España, edición preparada por Atilano Domínguez (Actas del Congreso Internacional sobre «Relaciones entre Spinoza y España», 1992, Almagro), Cuenca, Servicio de Publicaciones de la Universidad de Castilla-La Mancha, pp. 87-105.

Rolland, R. (1931). Empédocle d'Agrigente. L'éclair de Spinoza. París, Éditions du Sablier.

- (1959). Le voyage intérieur (Songe d'une vie), París, Albin Michel, (edición revisada y aumentada respecto a la edición inicial y parcial de 1942).

Saisset, E. (1862). «La Philosophie des Juifs, Maïmonide et Spinoza», Rérue des Deux Mondes, $2^{\mathrm{e}}$ période, tome 37, pp. 226-334.

- (1872). Oeuvres de Spinoza, 3 vols., París, Charpentier. Traducción e introducción crítica a cargo de Émile Saisset. Nueva edición revisada y aumentada respecto a la inicial de 1843.

SpinOzA, B. (1972). Spinoza Opera, 4 vols., Heidelberg, Carl Winters, 1972 (1ª ed.: 1925). Edición de Carl Gebhardt.

- (1988a). Correspondencia, Madrid, Alianza. Edición de Atilano Domínguez.

- (1988b). Tratado de la reforma del entendimiento. Principios de filosofía de Descartes. Pensamientos metafísicos, Madrid, Alianza, 1988. Traducción española de Atilano Domínguez.

- (2007), Ética demostrada según el orden geométrico, Madrid, Tecnos. Traducción, introducción y notas de Vidal Peña García. 
Vermorel, H. (2007). «Présence de Spinoza dans les échanges entre Romain Rolland et Sigmund Freud», Conferencia pronunciada en la Sorbona, el 31 de mayo de 2007, Études Rollandiennes, $\mathrm{n}^{\circ} 18$.

Vermorel, H. y Vermorel, M. (1993). Sigmund Freud et Romain Rolland. Correspondence 1923-1936, París, PUF.

Zweig, S. (1935). Romain Rolland. El hombre y la obra, Buenos Aires, Ediciones Imán (ed. original: Romain Rolland: der Mann und das Werk, 1921).

- (2001). El mundo de ayer. Memorias de un europeo, Barcelona, Acantilado (ed. original: Die Welt von Gestern. Erinnerungen eines Europäers, 1944).

Recibido: $27 / 10 / 2011$

Aceptado: 4/11/2011 